УДК 82.09:159.923

\title{
А.А. Харлушина
}

\section{ТРАНСФОРМАЦИЯ АДДИКЦИИ ГЛАВНОГО ГЕРОЯ ПОВЕСТИ И. С. ТУРГЕНЕВА «ПЕТУШКОВ»}

В статье проанализировано, как в повести И.С. Тургенева «Петушков» меняется жизнь главного героя, который из благородного офицера превращается в жалкого больного человека. Прослежено влияние женских «демонических» сил на судьбу поручика. Женский образ показан как сочетание нескольких типов тургеневских героинь. Утверждается, что, развивая тему «маленького человека», И.С. Тургенев не только обращается к гоголевской традиции, но и индивидуально-авторски интерпретирует ее.

Ключевые слова: И.С. Тургенев, повесть «Петушков», «маленький человек», зависимость главного героя, «тургеневская девушка», «демоническая женщина».

DOI: $10.35634 / 2412-9534-2021-31-6-1268-1272$

Повесть «Петушков» (1848 г.) относится к раннему периоду творчества И.С. Тургенева. В это время происходило становление личности писателя, поэтому обращение к представителям своего времени (в повести указывается $182 \ldots$ год) объясняется желанием не только объективно оценить прошлое, но и разобраться в самом себе. Создавая тот или иной портрет героя, автор невольно приоткрывает свою душу и детально познаёт собственный внутренний мир.

Принято считать, что повести Тургенева 1840-1850-х гг. описывают путь героя. Не исключением является и «Петушков». Рассмотрим, как изменяется судьба главного персонажа данного произведения, какими личностными качествами наделяет его писатель, и попытаемся показать трансформацию его зависимостей (пищевая - любовная - алкогольная), являющуюся результатом инволюции.

Образ поручика Ивана Афанасьевича Петушкова, безусловно, продолжает гоголевскую традицию изображения «маленького человека». О его сходстве с Акакием Акакиевичем («Шинель») упоминает П.Г. Пустовойт: «В своих поступках, поведении, чувствах Петушков так же жалок и одновременно смешон, как и гоголевский Башмачкин. Чувства Петушкова к Василисе мелки и робки; его мелкотравчатая ревность производит в высшей степени комическое впечатление, а его поведение отличается целым рядом странностей и нелепостей. Всё это Тургенев мастерски облекает в соответствующую форму - отражает в языке героя. Язык, которым Петушков изъясняется с людьми, напоминает косноязычие Акакия Акакиевича Башмачкина» [4]. Подобие Петушкова Башмачкину отмечает C.M. Петров: «Смешон и жалок Петушков с его ничем не просветленной любовью и тупой ревностью, с его косноязычной речью, с его бессмысленной жизнью, напоминающей жалкое существование гоголевского Акакия Акакиевича. Как и Башмачкину, тургеневскому герою присущи самоунижение и интеллектуальная бедность, боязливость и растерянность перед «значительным лицом» [3]. Даже идею выбора фамилии для своего героя И.С. Тургенев заимствовал у Н.В. Гоголя: она образована не от слова «петух» (у Гоголя - не от слова «башмак»), а от слова «петушок» (у Гоголя - от слова «башмачок») - «маленькому человеку» дана и фамилия с уменьшительным суффиксом. Однако образ тургеневского героя описан и в индивидуально-авторской манере. Как пишет Е.М. Сокол, «каждый писатель “натуральной школы”, интерпретировав гоголевскую “Шинель”, создаёт свою модификацию типа "маленького человека"» [5].

Знакомясь с судьбой Петушкова, следует принять во внимание одну важную деталь, о которой сообщает автор в начале произведения: «Петушков по утрам, за чаем, любил кушать свежую белую булку. Без этого лакомства он жить не мог» [6, с. 121]. Безобидной эта привычка остается до определенного момента, у героя возникает нездоровая зависимость от нее. Петушков отказывается от предлагаемого слугой завтрака: «Иван Афанасьевич прошёлся по комнате, оделся и сам отправился в булочную» [6, с. 122]. Однако и в булочной его постигает разочарование: на предложение хозяйки взять «крендель» или «паплюху» Петушков обижается. И когда племянница хозяйки заведения кокетливо угощает его булкой, он вновь обретает жизнерадостность и покой. После этого случая судьба Петушкова кардинально меняется. Однообразный, спокойный, размеренный образ жизни исчезает. Герой оказывается в любовном плену у молоденькой мещанки Василисы. 
Трансформация аддикции главного героя повести И.С. Тургенева «Петушков»

1269

И.С. Тургенев изображает внешне ничем не примечательную девушку. У нее «полное, круглое лицо», «нос, несколько вздёрнутый», «русые волосы», «глаза карие, небольшие». Но Петушков с первого взгляда влюбляется в Василису, и впадает в «ребяческое» состояние: «Целый день ему было неловко, и даже вечером он, против обыкновения, не пустился в разговор с Онисимом» [6, с. 124]. Случайная встреча с 17-летней мещанкой приводит к тому, что герой впадает в зависимость от ежедневного общения с Василисой: «Петушков страстно привязался к Василисе. Он был счастлив вполне. Его душа согрелась» [6, с. 133]. Между героями завязывается роман, однако без счастливой развязки. Василиса не отвечает офицеру взаимностью. Ей вскоре наскучивают встречи с 40-летним поручиком. Она негативно воспринимает оказываемые им знаки внимания и предпринимаемые для ее развития занятия: не хочет учиться грамоте, скучным и неинтересным ей кажется чтение книг. Наконец, Василиса изменят Петушкову. И герой в порыве гнева дает ей адекватную оценку: «Да ведь она деревяшка, совершенная деревяшка, необразованная мещанка!» [6, с. 143]. Тем не менее он переживает чувство ревности, когда Василиса уходит из дома, страдает от неразделённой любви. Живя в задней комнате при булочной, Петушков понимает ещё не совсем затуманенным разумом своё жалкое положение униженного влюблённого, однако ничего не может с собою поделать - его словно магнитом тянет к булочнице. Он не раз удивляется своему необъяснимо сильному чувству, которое не возвышает, а унижает его, преобразует из самодовольного офицера в нелепое существо: «По бледному его лицу катились слёзы, косичка волос торчала на темени, глаза глядели мутно... искривлённые губы дрожали... голова упала на грудь» [6, с. 147].

Однажды Петушков всё-таки решил окончательно расстаться с Василисой, но «...чуть не сошёл... с ума от тоски, ревности и скуки» [6, с. 155]. Любовь разрушает и губит его: офицер «раззнакомился с своими товарищами», равнодушно выслушивал советы слуги бросить хождения к булочнице. Не изменил ситуацию даже разговор с начальством. Вызвав Петушкова к себе, майор пытался всячески его пристыдить: «Сидит день-деньской в булочной; а ещё благородный! Юбка там завелась - вот он и сидит. Ну пусть бы её, юбку, к чёрту! А то, говорят, сам хлебы в печь сажает. Мундир марает...да» [6, с. 151]. Для Петушкова Василиса стала непостижимой роковой привязанностью, от которой он не имел возможности избавиться. Даже «...одни разговоры с Онисимом о Василисе доставляли ему некоторую отраду» [6, с. 155]. Повествователь неоднократно называет героя «бедным», сочувствуя его безысходному положению. «Бедный» Петушков осознаёт убийственную, роковую силу любви: «Я? Как видишь! Убит. И кем убит? Тобой убит, Василиса» [6, с. 159]. Аддикция приводит героя к дальнейшей деградации. Он начинает употреблять спиртное. Тут уместно вспомнить мысль Л.Б. Шнейдера о том, что любая аддикция/девиация - это «процесс маргинализации и направленных необратимых деструктивных изменений личности, разрушения и отмирания её смысловых образований» $[8$, с. 66].

В финале повести Петушков превращается в жалкого, потерявшего собственное достоинство, больного, никому не нужного пьяницу: «Стал он худеть и бледнеть, ел неохотно и торопливо, трубки вовсе не курил» [6, с. 156]. При этом герою легче существовать в каморке при булочной, продолжать любить и ревновать уже замужнюю Василису, «запивая» свою боль алкоголем, чем жить порознь с ней. Алкогольная зависимость героя развивается стремительно. В начале предпоследней главы повествователь намекает о том, что нёс домой под шинелью Петушков, а потом описывает стоящую на окне пустую тёмно-зелёную бутылку с надписью «Ром Ямайский самый лучший». А в последней главе изображается «красненький носик» и лишь одна слабость повзрослевшего на десять лет Ивана Афанасьевича: «...любил выпить, впрочем, вёл себя смирно» [6, с. 160].

Мы рассмотрели, как трансформировалась пищевая аддикция героя к концу повести. Потребность в булке по утрам, описанная в начале произведения, перешла в тяжелую любовную зависимость от женщины. Безответная любовь приводит Петушкова к новой - алкогольной зависимости.

Как правило, аддикции разного рода возникают вследствие слабохарактерности и безволия человека. Именно эти качества «слабого», «бесхребетного», «смешного» (по словам П.Г. Пустовойта) существа явились первопричиной зависимостей Петушкова. Однако влияние «демоничности» женского образа на судьбу поручика нельзя упускать из вида. Рассмотрим подробнее образ Василисы и попытаемся соотнести её с разными типами тургеневских героинь.

Как уже говорилось, автор не только не наделил свою героиню примечательной внешностью, но и показал её недалёкой умом. В лице Василисы писатель явно хотел передать черты умственной и речевой ограниченности мещанской среды. Все интересы героини связаны с низменно-бытовой стороной жизни человека: погулять да блинов на печи поесть. Однако в описание прозаичной внешности Васи- 
лисы Тургенев добавил «великолепные плечи», которые притягивали взоры многих «любезных» и «развязных» молодых людей типа Бублицына и были, вероятно, одной из причин ревности Петушкова.

Какими же силами могла так сильно привязать к себе простая булочница добропорядочного и «не бесчиновного» человека? Онисим, слуга Ивана Афанасьевича, считает власть Василисы над героем колдовской: «Зелья, что ли, она какого дала вам?», «Вот уж точно можно сказать: полюбится сатана пуще ясного сокола» $[6$, с. 146]. И это даёт все основания отнести данную героиню к типу «демонической женщины». По мнению исследователя женских образов в повестях И.С. Тургенева О.В. Дедюхиной, образ «демонической женщины» «...обнаруживается в повестях, изображающих любовь как роковую власть, подчиняющую волю» [1, с. 105]. Именно это можно наблюдать в рассматриваемой нами повести, героиня которой беззастенчиво демонстрирует свои инфернальные качества. Когда Иван Афанасьевич, после долгого отсутствия Василисы, ждал от нее каких-либо объяснений, «...Василиса смело взглянула ему в глаза, нагло засмеялась и, не давши ему выговорить слова, проворно вошла в свою комнату и заперлась» [6, с. 146].

В результате своей ограниченности Василиса не осознавала силу демонической власти над героем, она не понимала его роковой привязанности и не сочувствовала ему. Когда Онисим пришёл просить героиню навестить барина и хоть как-то посочувствовать ему, попытаться исправить его плачевное состояние, она высказала недоумение: «Так чем же я виновата? Чем же я помочь-то могу?» [6, с. 157]. Такие качества личности позволяют отнести героиню к типу «демонический женщины».

Писатель в своих произведениях создал противоположный тип - «тургеневской девушки», получивший устойчивую номинативность еще при его жизни. Доминантными чертами «тургеневской девушки» исследователи считают юность, нравственную чистоту, скромность, чувствительность, цельность, стремление к саморазвитию и поиску высокой любви. Безусловно, в Василисе нет этих качеств. Но, как отмечает О.Б. Шакирова, одной из черт «тургеневской девушки» является отсутствие выразительной внешности: «Яркой красотой она не отличается, часто может восприниматься как дурнушка» [7, с. 5]. Тем не менее эта героиня притягательная, волевая и свободная в поступках. Василиса тоже лишена яркого внешнего облика. Ее нельзя сравнивать с «демоничскими женщинами», описанными, к примеру, в романе «Отцы и дети»: с самоуверенной красавицей Анной Сергеевной Одинцовой и «роковой красавицей» графиней $\mathrm{N}$, возлюбленной Николая Петровича Кирсанова, а также с надменной помещицей, имевшей волевые черты лица, Аграфеной Ивановной из повести «Бригадир». Как пишет О.В. Дедюхина, «во внешнем облике Василисы автор подчеркивает простоту, обыкновенность и чувственную привлекательность» [1, с. 105]. Отсутствие внешней красоты, загадочная привлекательность, а также самоволие делают Василису образом, сочетающим черты разных женских типов, описанных И.С. Тургеневым, и не ставшим пока объектом пристального внимания исследователей.

Два образа повести - мужской и женский можно рассматривать в качестве отдельных, самостоятельных и в тесной взаимосвязи друг с другом. Показав в Петушкове психологический тип «маленького человека», И.С. Тургенев развил традицию Гоголя до прозрения будущего чеховского героя. Но драму падения личности, изображенную в повести, можно проецировать и на общественное неблагополучие. Справедливо заметила Л.М. Лотман, указав, что у Тургенева «личная трагедия, трагедия неудачной любви выступала как отражение трагических общественных противоречий» [2, с. 567]. С ее точки зрения, писатель «...подвергал критике проявления покорности, слабости, трусости, неверия в собственные силы. Тургенев отмечал, что обиженные, обездоленные люди <.. > тяжело переживают свое бессилие в борьбе в тех случаях, когда они оказываются перед необходимостью «смириться» [2, с. 551]. На примере ранней тургеневской повести мы рассмотрели художественно воплощенное психологическое исследование слабохарактерности, которая может привести к разного рода аддикциям. Переходя от одной зависмости к другой, герой впадает в наиболее тяжелую форму самоотчуждения и саморазрушения. При этом, помимо природных черт характера, роковую роль в его судьбе играет внеличная сила любви, которая бессознательно внушена женщиной.

\section{СПИСОК ИСТОЧНИКОВ И ЛИТЕРАТУРЫ:}

1. Дедюхина О.В. Образ демонической женщины в повестях И.С. Тургенева. // Интерактивная наука. 2016. № 10. С. 105-108.

2. Лотман Л.М. Проза сороковых годов [ХІХ века] // История русской литературы: в 10 т. / АН СССР. Ин-т рус. лит. (Пушкин. Дом). М.; Л.: Изд-во АН СССР, 1941-1956. Т. VII. Литература 1840-х годов. 1955. С. 511-570. URL: http://feb-web.ru/feb/irl/il0/il7/i17-5112.htm (дата обращения: 21.07.2020). 
3. Петров С.M. И.С. Тургенев. Творческий путь. М.: Художественная литература, 1961. 592 c. URL: http://i-sturgenev.ru/books/item/f00/s00/z0000012/st002.shtml (дата обращения: 22.07.2020).

4. Пустовойт П.Г. Сатирические тенденции в творчестве И.С. Тургенева. URL: http://turgenev-lit.ru/turgenev/ kritika-o-turgeneve/tvorchestvo-turgeneva-sbornik/pustovojt-satiricheskie-tendencii-v-tvorchestve-turgeneva.htm (дата обращения: 20.07.2020).

5. Сокол Е.М. «Маленький человек» в творчестве русских писателей $1840-$ х годов в свете христианской традиции: От Гоголя-к Достоевскому: диссертация. URL: https://www.dissercat.com/content/malenkii-chelovek-vtvorchestve-russkikh-pisatelei-1840-kh-godov-v-svete-khristianskoi-tradi (дата обращения: 20.07.2020).

6. Тургенев И.С. Собрание сочинений. В 12-ти томах. Ред. коллегия: М.П. Алексеев, Г.А. Бялый. Т. 5. Повести и рассказы 1844-1853. Примеч. В.Д. Сквозникова. М.: Художественная литература, 1977. 413 с.

7. Шакирова О.Б. Тургеневская девушка: вчера и завтра: дайджест. Миасс: МКУ «ЦБС», 2018. 38 с. URL: http://miasslib.ru/wp-content/uploads/2018/11/\%D0\%A2\%D1\%83\%D1\%80\%D0\%B3\%D0\%B5\%D0\%BD\%D0\% B5\%D0\%B2\%D1\%81\%D0\%BA\%D0\%B0\%D1\%8F-\%D0\%B4\%D0\%B5\%D0\%B2\%D1\%83\%D1\%88\%D0\%BA\% D0\%B0.pdf (дата обращения: 05.07.2020).

8. Шнейдер Л.Б. Психология подростковой девиантности и аддиктивности. М.: Изд-во Московского психологосоциального университета, 2016. 300 с.

Поступила в редакцию 25.12.2020

Харлушина Алла Александровна, кандидат филологических, старший преподаватель кафедры общей и прикладной филологии ФГБОУ ВО «Ярославский государственный университет им. П.Г. Демидова» 150003, Россия, г. Ярославль, ул. Советская, 14 E-mail: alla-la28yanv@mail.ru

\section{A.A. Kharlushina \\ TRANSFORMATION OF DEPENDENCE OF THE PROTAGONIST OF IVAN TURGENEV'S STORY "PETUSHKOV"}

DOI: $10.35634 / 2412-9534-2021-31-6-1268-1272$

This article shows how in I.S. Turgenev's story "Petushkov" the life of the protagonist changes: he turns from a noble officer into a miserable sick person. The work talks about the influence of female "demonic" forces on the fate of the lieutenant. An attempt is made to show the female image as a combination of several types of Turgenev's heroines. The development of the theme of a "little man" is shown not only as the embodiment of the Gogol tradition, but also as the author's interpretation of it.

Keywords: I.S. Turgenev, the story "Petushkov", "little man", dependence of the main character, "Turgenev's girl", "demonic woman".

\section{REFERENCES}

1. Dedyuhina O.V. Obraz demonicheskoj zhenshchiny v povestyah I.S. Turgeneva [The image of a demonic woman in the novels of I.S. Turgenev]. // Interaktivnaya nauka. 2016. №10. S. 105-108. (In Russian)

2. Lotman L.M. Proza sorokovyh godov [XIX veka] [The prose of the forties [of the nineteenth century]. // Istoriya russkoj literatury: V 10 t. / AN SSSR. In-t rus. lit. (Pushkin. Dom). M.; L.: Izd-vo AN SSSR, 1941-1956. T. VII. Literatura 1840-h godov. 1955. S. 511-570. URL: http://feb-web.ru/feb/irl/il0/il7/il7-5112.htm (data obrashcheniya: 21.07.2020) (In Russian).

3. Petrov S.M. I.S. Turgenev. Tvorcheskij put' [I. S. Turgenev. Creative way]. M.: Hudozhestvennaya literatura, 1961. 592 s. URL: http://i-s-turgenev.ru/books/item/f00/s00/z0000012/st002.shtml (data obrashcheniya: 22.07.2020) (In Russian).

4. Pustovojt P.G. Satiricheskie tendencii v tvorchestve I.S. Turgeneva [Satirical tendencies in the works of I.S. Turgenev]. URL: http://turgenev-lit.ru/turgenev/kritika-o-turgeneve/tvorchestvo-turgeneva-sbornik/pustovojt-satiricheskietendencii-v-tvorchestve-turgeneva.htm (data obrashcheniya: 20.07. 2020) (In Russian)/

5. Sokol E.M. "Malen'kij chelovek" v tvorchestve russkih pisatelej 1840-h godov v svete hristianskoj tradicii: ot Gogolyak Dostoevskomu ["Little man" in the works of Russian writers of the 1840s in the light of the Christian tradition: from Gogol to Dostoevsky]: Dissertaciya. URL: https://www.dissercat.com/content/malenkii-chelovek-v-tvorchestverusskikh-pisatelei-1840-kh-godov-v-svete-khristianskoi-tradi (data obrashcheniya: 20.07.2020) (In Russian).

6. Turgenev I.S. Sobranie sochinenij [Collected works]. V 12-ti tomah. Red. kollegiya: M.P. Alekseev, G.A. Byalyj. 
T.5. Povesti i rasskazy 1844-1853. Primech. V.D. Skvoznikova. M.: Hudozhestvennaya literatura, 1977. 413 s. (In Russian)/

7. Shakirova O.B. Turgenevskaya devushka: vchera i zavtra [Turgenev's girl: yesterday and tomorrow]: dajdzhest. Miass: MKU «CBS», 2018. 38 s. URL: http://miasslib.ru/wp-content/uploads/2018/11/\%d0\%a2\%d1\%83\%d1\%80\% d0\%b3\%d0\%b5\%d0\%bd\%d0\%b5\%d0\%b2\%d1\%81\%d0\%ba\%d0\%b0\%d1\%8f-\%d0\%b4\%d0\%b5\%d0\%b2\%d1\% $83 \% \mathrm{~d} 1 \% 88 \% \mathrm{~d} 0 \% \mathrm{ba} \% \mathrm{~d} 0 \% \mathrm{~b} 0 . \mathrm{pdf}$ (data obrashcheniya: 05.07.2020) (In Russian)/

8. Shnejder L.B. Psihologiya podrostkovoj deviantnosti i addiktivnosti [Psychology of adolescent deviance and addiction]. M.: izd-vo moskovskogo psihologo-social'nogo universiteta, 2016. 300 s. (In Russian)

Received 25.12.2020

Kharlushina A.A., Candidate of Philology, Senior Lecturer at Department of General and Applied Philology Yaroslavl State University named after P.G. Demidov

Sovetskaya st., 14, Yaroslavl, Russia, 150003

E-mail: alla-la28yanv@mail.ru 